\title{
Cognitive liberty
}

\section{Protecting the right to neuroenhancement}

\author{
Arthur Shuster (Meds 2017), Adriana Cappelletti (Meds 2018) \\ Faculty Reviewer: Dr Jackie Sullivan, PhD (Department of Philosophy)
}

\section{INTRODUCTION}

Advances in neuroscience and biotechnology in recent decades have opened up unprecedented possibilities for altering and modifying the human brain to enhance cognitive and mental functions. Although one gets the impression that much of the current neuroscience research in "mind enhancement" is still only nascent, in the case of certain studies it is already possible to see clearly their implications for-and consequently their challenges to-some of our current medical, legal and cultural conventions. Take, for instance, the example of recent research in a neuroscience field called optogenetics. In 2013, a group of neuroscientists developed a way of inducing a "false memory" in experimental mice. These researchers had identified a specific population of neurons in the dentate gyrus of an animal subject's hippocampus, known to be involved in memory formation and storage, that was naturally activated whenever the animal was exposed to painful stimulus (eg electric shock). These neurons would be reactivated in the future in response to the same or similar context, even in absence of the painful stimulus, producing a fear response-that is, because a "fear memory" had been formed. By reactivating these same cells artificially (using light energy-hence the name, optogenetics) in a different context than the one used to condition the original fear memory, the fear response could again be elicited in the animal subject, this time to an entirely new context-thus forming a "false memory." If extrapolated to the human brain, these and similar discoveries in nanotechnology, biotechnology, information technology, and cognitive science (NBIC), open up exciting and in some cases potentially alarming new possibilities. The imaginable applications of such techniques span a spectrum, from medical therapies that could cure individuals traumatized by abuse to the ominous spectre of a government reprogramming the minds of criminals and perhaps political dissidents.

\section{COGNITIVE LIBERTY}

Recently, an attempt has been made to confront the issue of NBIC technology as a moral-philosophical problem by articulating the novel ethical concept of "cognitive liberty." According to Sententia, a leading neuroethicist on this subject, cognitive liberty is the idea that every person has a fundamental right not only to think independently (a right already contained in liberalism's commitment to 'freedom of thought,' as defended by J. S. Mill), but also "to have autonomy over his or her own brain chemistry." It would seem to follow that, as a fundamental right, cognitive liberty would require strong legal protections for the private use of neuroenhancement (NE) technologies. ${ }^{2}$ This view of cognitive liberty as a fundamental right directly challenges a number of contemporary norms. For instance, it seems to imply the need to protect the recreational use of psychotropic drugs, a practice that is currently illegal in many places.

From a philosophical standpoint, there are opposing stances on how NE shapes the definition of being a self: the essentialist viewpoint that $\mathrm{NE}$ compromises what it means to be a person, and the existentialist opinion that $\mathrm{NE}$ is a choice people can make as the agents of their own development. According to theologian Alan Watts, there is a longstanding view within Western culture of the person as an "individual, self-determining, responsible ego." Essentialists would argue that NE jeopardizes this definition of personhood and compromises the "authenticity of persons" by interfering with individuals' natural journey of self-discovery and personal growth. ${ }^{4}$ Individuals might confuse their understanding of themselves as they are with that of their neuroenhanced selves. Conversely, existentialists would support NE, as they believe that acting as the responsible agent of one's development is a fundamental part of being a person. It follows that actively shaping who one wants to be includes how one wants to think, under the influence of NE or not. So long as these NE interventions pose low risk to health, should individuals not have the right to benefit from their enhancing effects? ${ }^{3}$

Ethical issues of cognitive liberty also concern the social impact of NE. On one hand, society as a whole might benefit from NBIC-related medical innovation; thus, one could argue that there is an obligation to pursue research into NBIC-related technologies such as optogenetics. Yet one might also have reason to fear that unequal access to memory- and attention-improving tools could increase social inequality within our society. In an era of competitive job markets and information overload, those who can access and afford NE may be perceived as having an unfair advantage over those who cannot. Ethicists have raised concerns over how increasing the standard of cognitive fitness within such a competitive environment might actually impede rather than enhance cognitive liberty, as non-users will feel pressured to use NE in order to keep up with their cognitively advantaged peers. ${ }^{4}$

\section{LEGAL AND SOCIAL DIMENSIONS}

Cognitive liberty is implicit in the freedoms of thought and action. ${ }^{3,4}$ However, proponents of $\mathrm{NE}$ argue that cognitive liberty and its boundaries must be explicitly defined within positive law in order for individuals to be protected in their elective use of NE and protected from government imposition of NE. ${ }^{3}$ Proponents of 
elective NE use would argue that the value society places on bodily integrity (the autonomy of persons over their own bodies) supports the legal right to cognitive liberty. ${ }^{5}$ Our legal system allows individuals to engage in behaviours that put the physical body at risk, such as extreme sports. Instead of prohibiting these activities, regulations are put in place to ensure safety and informed consent, and the onus is placed on the individual to determine whether the behaviour is appropriate. ${ }^{4}$ Given that individuals are allowed to make informed decisions regarding behaviours with potential physical harms, how can behaviours with neurologic effects be criminalized? After all, the nervous system is part of the physical body. This question is especially relevant to NE with low risk-profiles, as the harm principle, which states that power cannot be exercised against a civilized community's will unless it is to prevent harm, is a precursor to criminalization. ${ }^{3,6}$ The counterargument to this notion is that mind and body are distinct, as are our understandings of these entities. Injury to the body is well researched, whereas the definition of "illegitimate mental harm" remains unclear. ${ }^{4}$ Critics of NE would argue that it is counterintuitive to draft policies in support of $\mathrm{NE}$ while our understanding of the mind remains limited and fully informed decisions about its use cannot be made. Nevertheless, as our knowledge of brain function is expanding, policy-makers must consider explicitly defining cognitive liberty within positive law in order to lay the foundations for safe and regulated use of NE in the future. ${ }^{2}$

Although no court has yet ruled on a cognitive liberty case, there are precedents in other areas of constitutional case law that help us predict how courts might decide on the question of cognitive liberty in the future. Constitutional guarantees of individual rights in Canada and the United States strongly reflect the harm principle, yet the courts have not applied this principle in a consistent or unqualified way. Rather, the courts have restricted individual liberty in a wide range of areas of private life, such as prohibiting the recreational use of some drugs (methamphetamines) and not others (nicotine and alcohol); allowing the sex industry to exist, but banning prostitution; and allowing self-harm, but only up to a point-namely, not to the point of suicide. The reason for this is that the courts have recognized other principles enshrined in the law that are distinct from the harm principle. Section 1 of the Charter of Rights and Freedoms accepts that "reasonable limits" to fundamental individual freedoms may be prescribed by law in order to uphold a "free and democratic society," and in accordance with this constitutional provision the Supreme Court of Canada (in R. v Oakes) has established precedents for limiting individual freedoms as a way of defending "collective goals of fundamental importance." Thus, for example, in 1993 the Canadian Supreme Court ruled in R. v. Tremblay, a case involving sex trade workers in Quebec, that the law may restrict individual liberty in accordance with a "community standard of tolerance"-in this case, for acts of "anti-social" indecency. The court considered this community standard to be a legitimate imposition on individual liberty that was consistent with a liberal constitution. ${ }^{8}$
In these and other such cases, the courts have recognized the need to balance the common good against individual autonomy, following a long tradition of democratic thought, from Aristotle up to the intellectual founders of the Anglo-American republic, that has understood a functioning political order as deriving at least some of its stability from a certain moral consensus or majority opinionwhether that opinion is more enlightened, or less. ${ }^{9,10}$ The question, then, is whether it is likely that the majority moral opinion can now or will in the future be able to tolerate such practices-psychotropic drugs, optogenetic memory alteration, cognitive enhancement-as are defended by advocates of cognitive liberty. For now, it can only be said that it will likely be able to tolerate some (eg certain medical therapies), but not others (eg hallucinatory recreational drugs, or their NE equivalents). This is complicated by the possibility that the majority moral opinion of a community may change over time. Democratic regulation of $\mathrm{NE}$ will continue to be a challenge within our ever-evolving society.

\section{REFERENCES}

1. Liu X, Ramirez S et al. Inception of a false memory by optogenetic manipulation of a hippocampal memory engram. Philos Trans R Soc Lond B Biol Sci. 2014 Jan; 369(1633):1-7.

2. Sententia W. Neuroethical considerations: cognitive liberty and converging technologies for improving human cognition. Ann N Y Acad Sci. 2004 May;1013(1):221-8.

3. Walsh C. Beyond Religious Freedom: Psychedelics and Cognitive Liberty. In: Prohibition, Religious Freedom, and Human Rights: Regulating Traditional Drug Use. Berlin, Heidelberg: Springer; 2014. p. 211-33.

4. Bublitz JC. My mind is mine!? Cognitive liberty as a legal concept. In: Cognitive Enhancement. Springer Netherlands; 2013. p. 233-64.

5. Miller RA. The Limits of Bodily Integrity: Abortion, Adultery, and Rape Legislation in Comparative Perspective. Ashgate Publishing, Ltd.; 2007.

6. Mill JS. On Liberty. Indianapolis: Hackett Publishing; 1978.

7. R. v Oakes. 1986.1 S. C. R. 103.

8. R. v. Tremblay. 1993. 2 S. C. R. 932.

9. Aristotle. Politics. Trans. P. Phillips. Chapel Hill: University of North Carolina Press; 1997.

10. Rossiter C, ed. The Federalist Papers. Toronto: Penguin, 1999. 